Resenhas 



\section{O cientista e o político - Mario Schenberg}

Silvio r. A. Salinas ${ }^{I}$

E. SSE texto de Dina Lida Kinoshita é a biografia política de um militante notável, intelectual que se manteve fiel às perspectivas socialistas desde a sua juventude, e que foi também um dos grandes cientistas brasileiros. Como é bem descrito no texto, Mario Schenberg foi homem de partido, participante ativo das lutas democráticas no país. Mas era um militante muito especial, pois foi um daqueles intelectuais de formação e interesse amplos, herdeiros do Renascimento e do Iluminismo, que fazem muita falta na cultura especializada do país contemporâneo. Além de físico teórico de trânsito internacional, com trabalhos de pesquisa científica admirados pelos seus pares, Mario Schenberg foi colecionador e crítico de arte, contribuindo para a carreira de diversos artistas brasileiros.

Mario Schenberg nasceu em Recife, filho de pais imigrantes europeus. Iniciou o curso universitário na antiga Escola de Engenharia de Recife, mas se transferiu para a Escola Politécnica de São Paulo em 1933. No ano seguinte foi fundada a Universidade de São Paulo, que trouxe ao país os primeiros professores estrangeiros para iniciar os cursos de ciências e humanidades da nova Faculdade de Filosofia, Ciências e Letras. Essa deve ter sido uma época maravilhosa. A física do século XX já havia passado por enormes transformações, associadas à teoria da relatividade e à nova mecânica quântica, mas que ainda não tinham chegado ao país. Alguns alunos da Escola Politécnica se encantaram com as aulas de um físico excepcional, Gleb Wataghin, de origem italiana, e se transformaram nos fundadores da física moderna no Brasil. Mario Schenberg era o físico teórico desse grupo. A partir de 1936, quando publicou o seu primeiro trabalho científico numa revista italiana de muito prestígio, sobre problemas da "eletrodinâmica quântica", Schenberg manteve uma produção científica respeitadíssima no Brasil e no exterior, que há pouco tempo foi recuperada em dois alentados volumes publicados pela Editora da Universidade de São Paulo.

Estimulado pelo ambiente da universidade que se organizava, Schenberg fez longas viagens ao exterior. Ainda antes da Segunda Guerra, trabalhou em Roma, junto ao grupo de Enrico Fermi, um dos maiores físicos do século XX, mas também esteve na Suíça e na França. Essas viagens devem ter sido intelectualmente marcantes. Mais tarde ele mesmo relata que gostou muito da Itália, “onde me identifiquei com o povo e vi muita coisa sobre arte. Foi quando comecei a me interessar de novo pela arte. Em Paris, conheci Di Cavalcanti, que tinha um atelier junto com De Chirico. Foi muito interessante fazer essa viagem à Europa, antes da guerra. Paris antes da guerra era outra coisa. Foi um mundo que ainda pude conhecer e que desapareceu ...." Schenberg também viaja para os Estados Unidos, durante a Guerra, colaborando em dois trabalhos sobre a "evolução das estrelas", problemas importantes da área de astrofísica que ainda são muito lembrados. Num desses trabalhos, com George Gamow, aparece a proposta do "efeito Urca" para explicar a explosão 


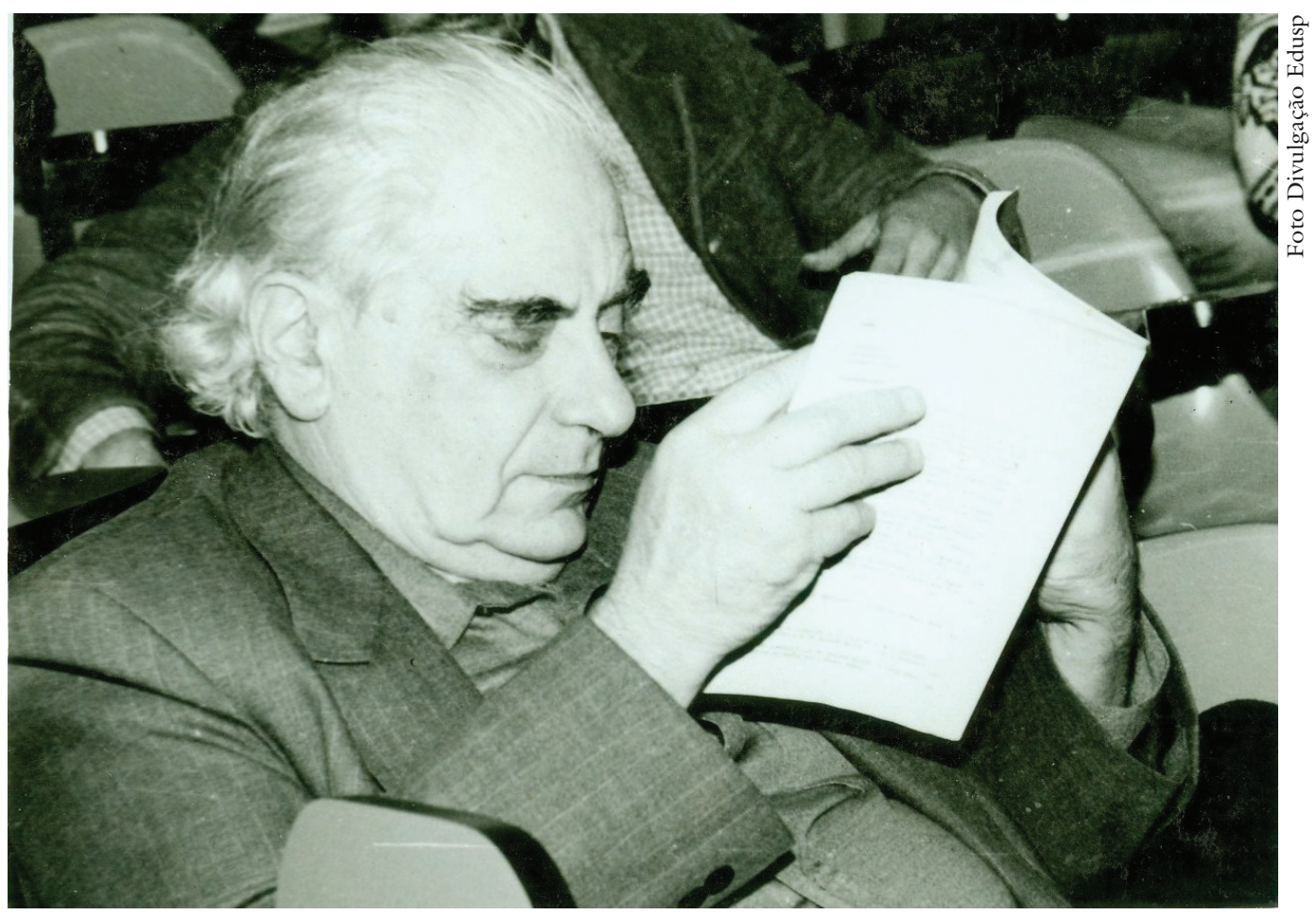

Mario Schenberg (1914-1990).

estelar; as estrelas perdem muita energia, rapidamente, que é carregada pelos neutrinos postulados por Fermi, da mesma maneira como grandes fortunas trocam de mão, rapidamente, nas mesas de jogo do Cassino da Urca .... Em 1944, esse cientista que "pensava nas estrelas" substitui Monteiro Lobato como paraninfo da turma de formandos da Faculdade de Filosofia da USP. Faz então um discurso, reproduzido nessa biografia, que é um bom resumo das preocupações da época, no final da Guerra, com amplas perspectivas democráticas para o mundo e para o país. Essas preocupações democráticas, abaladas pela "guerra fria", vão ser uma constante nos artigos e pronunciamentos políticos de Mario Schenberg nos anos seguintes.

Um dos retratos mais fieis de Mario Schenberg foi traçado num poema do seu amigo Haroldo de Campos,
“... o olhar transfinito do mário ... nos ensina ... a ponderar melhor a indecifrada ... equação cósmica .... na estante de mário ... física e poesia coexistem ... como asas de um pássaro - espaço curvo - ... colhidas pela têmpera absoluta de volpi..."

O "espaço curvo ... como as asas de um pássaro" é uma lembrança da geometria não euclidiana da relatividade, que dominou o trabalho de maturidade do professor Schenberg. Os alunos que visitavam a sua casa, para longas conversas sobre física e filosofia, como era muito comum nos anos 50 e 60 , ou então para os indefectíveis "exames orais", conheciam a "estante do Mario". Os livros, sobre todos os assuntos, eram muito bem encadernados; ele até emprestava para consulta, mas recomendava sempre "muito cuidado". Além dos livros, havia os quadros, quadros por toda a parte, 
empilhados e ocupando todo o espaço das paredes, de pintores nacionais como Volpi, que ele valorizava. Eu me lembro de um óleo de Pancetti, com um marinheiro de boina e a inscrição "anistia".

O poema de Haroldo de Campos contém ainda uma referência ao "marxismo zen" de Mario Schenberg, que ... "é dialético ... e dialógico.... e deixa ver que a sabedoria .... pode ser tocável como uma planta ... que cresce das raízes e deita folhas .... e viça ... e logo se resolve numa flor de lótus”. Como está registrado em várias passagens dessa biografia, Schenberg é um marxista heterodoxo e antiestalinista, muito antes da morte de Stalin e do XX Congresso do PCUS. Schenberg sempre pertenceu à "alma civilista", institucional, parlamentar e democrática, do comunismo brasileiro. Nos anos 1950, a USP acolheu David Bohm, notável físico americano, refugiado do maccartismo, que se lembrava de algumas conversas com Schenberg, especialmente das suas "lições de dialética hegeliana"...

Há várias questões que acompanharam a trajetória de Mario Schenberg e que aparecem muito bem retratadas nessa biografia. Ele sempre foi um defensor da pesquisa científica universitária, do desenvolvimento tecnológico nacional, e da educação de qualidade. Assumindo uma cadeira na Assembleia Legislativa, defendeu a criação de cursos universitários no interior, inclusive no período noturno, apontando a importância da dedicação integral e das bolsas de estudo para os alunos habilitados (como ele tinha visto em Princeton, nos Estados Unidos). No início da década de 1960, como chefe do Departamento de Física na USP, contando com promessas de apoio federal, promoveu a duplicação de

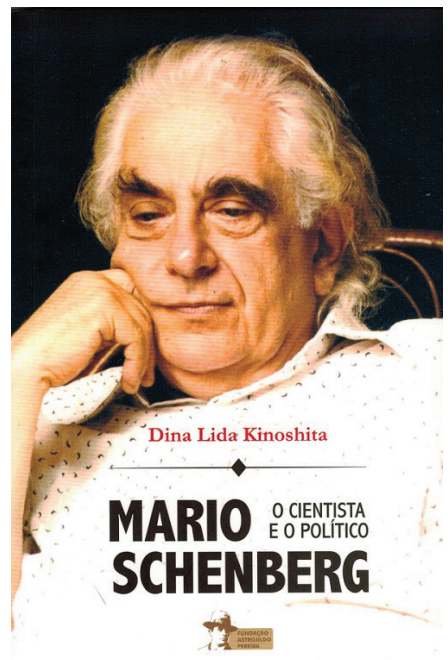

\section{KINOSHITA, D. L. Mario Schenberg. \\ O cientista e o politico. Brasília:}

Fundação Astrojildo Pereira, 2014. 299p.

vagas no curso de física para que o país dispusesse de pessoal altamente qualificado. Intuindo a importância de novas áreas, como a física dos semicondutores, propôs a expansão dos laboratórios de pesquisa, que eram muito restritos à física nuclear.

As questões da paz mundial o acompanharam desde a juventude. Em meados do século XX estava muito claro para Mario Schenberg que a organização de um mundo mais justo e democrático passava pela luta contra as ameaças de um conflito nuclear. Ele então se torna um dos primeiros proponentes da colaboração pacífica entre capitalismo e comunismo, como está registrado em vários trechos dessa biografia. Também antevê um papel positivo da Igreja Católica em países como o Brasil, muito antes do Concílio Vaticano II. Mario Schenberg foi membro do Conselho Mundial da Paz; escreveu artigos e participou de debates a favor do desarmamento nu- 
clear global, participou de forma ativa dos debates sobre a energia nuclear no Brasil, com muitas críticas a certas questões, como a política do tório e o acordo nuclear com a Alemanha. Chegou a antever a relevância da questão ambiental, que não era levada em consideração na sua época. Todos esses debates são abordados com propriedade nessa biografia política.

Esse texto preenche uma lacuna importante, trazendo ao público mais jovem a visão política de um dos nossos grandes cientistas.

Maio de 2014

Silvio R. A. Salinas é professor do Instituto de Física da Universidade de São Paulo. @ - ssalinas@if.usp.br 